\title{
Rabbit Model of Retinoblastoma
}

\author{
Shin Jeong Kang and Hans E. Grossniklaus \\ L.F. Montgomery Ophthalmic Pathology Laboratory, Department of Ophthalmology, Emory Eye Center, \\ Emory University School of Medicine, 1365-B Clifton Road NE, Atlanta, GA 30322, USA
}

Correspondence should be addressed to Hans E. Grossniklaus, ophtheg@emory.edu

Received 14 September 2010; Accepted 9 December 2010

Academic Editor: Monica Fedele

Copyright ( $) 2011$ S. J. Kang and H. E. Grossniklaus. This is an open access article distributed under the Creative Commons Attribution License, which permits unrestricted use, distribution, and reproduction in any medium, provided the original work is properly cited.

\begin{abstract}
We created a rabbit model of retinoblastoma and confirmed the tumor clinically and histopathologically. Seventeen New Zealand rabbits were immunosuppressed with cyclosporin A at doses of $10-15 \mathrm{mg} / \mathrm{kg}$. At day 3 , the animals received a $30 \mu \mathrm{l}$ subretinal injection of $1 \times 10^{6}$ cultured WERI retinoblastoma cells. Digital fundus images were captured before euthanasia, and the eyes were submitted for histopathology. Retinoblastoma cells grew in all the inoculated eyes and established a tumor under the retina and/or in the vitreous. New blood vessels in the tumor were observed starting at week 5. Cuffs of viable tumor cells surrounded the blood vessels with regions of necrosis present at 70-80 $\mu \mathrm{m}$ from nutrient vessels. Occasional tumor seeds in the vitreous histologically exhibited central necrosis. This rabbit model demonstrated similar fundus appearance and pathologic features to human retinoblastoma and may be used as a model to test various routes of drug delivery for retinoblastoma.
\end{abstract}

\section{Introduction}

Retinoblastoma is the most common primary intraocular tumor in childhood with an incidence of 1 in 20,000 live births. When left untreated, retinoblastoma is almost always fatal, but more than $95 \%$ of patients survive if they are treated before the tumor spreads outside the eye. Retinoblastoma is initiated by mutations in both alleles of the RB1 tumor suppressor gene. In about half of the children, the disease is hereditary, causing a predisposition to bilateral retinoblastoma and a risk of second malignancies. This risk of second malignancies is greater than $50 \%$ by the age of 50 years if the retinoblastoma is treated with external beam radiation (EBRT) [1], particularly in children less than 1 year of age [2]. Anticancer chemotherapeutic agents such as cyclophosphamide might have contributed to the high incidence of secondary tumors in children with RB1 mutations who also received EBRT [3]. Radiation also causes orbital deformities and cataracts if the tumor is located anteriorly.

Small, localized tumors can sometimes be treated using laser therapy or cryotherapy. Systemic chemotherapy can cause significant systemic toxicity like secondary leukemia or secondary malignancy, even if the complication rates remain acceptable $[4,5]$. Prolonged use of chemotherapy, especially at higher doses, may be associated with the development of multidrug resistance [6]. Delivery of drug locally to the eye has been suggested with high efficacy and limited systemic toxicity [7], but it can be associated with toxicity to the surrounding ocular tissues [8].

Animal models of retinoblastoma have been developed to study new therapies for this disease. A transgenic murine model of retinoblastoma has been introduced [9], but it is not available in larger animals.

Our goal was to create a rabbit model for retinoblastoma to study transscleral drug delivery. The main advantage for the use of rabbits is their larger eye size, which may serve as a model for local, targeted drug delivery platforms to human eyes with retinoblastoma. Blanco and coworkers developed a rabbit ocular melanoma model by injecting human uveal melanoma cells into the eyes of immunosuppressed rabbits [10]. The rabbits were immunosuppressed by daily intramuscular injection of cyclosporin, and cultured human uveal melanoma cells were injected into the suprachoroidal space of the rabbit eyes. Eighty-nine percent of the animals showed intraocular tumors starting 1 week after injection. 
Additionally, an animal model of retinoblastoma has been developed by injecting cultured human retinoblastoma cells into the vitreal cavities of immunodeficient mice [11].

\section{Methods and Materials}

2.1. Animals and Induction of Immunosuppression. All animal procedures were approved by Institutional Animal Care and Use Committee of Emory University and conformed to the Association for Research in Vision and Ophthalmology statement for the Use of Animals in Ophthalmic and Vision Research. Seventeen male New Zealand albino rabbits with a mean initial weight around $3 \mathrm{~kg}$ were used in this study. The rabbits were immunosuppressed with daily intramuscular injections of cyclosporin A (CsA; Sandimmune $50 \mathrm{mg} / \mathrm{mL}$; Novartis Pharmaceuticals, Cambridge, MA, USA). CsA administration was maintained throughout the 8-week experiment to prevent spontaneous tumor regression. The dosage schedule was $15 \mathrm{mg} / \mathrm{kg}$ per day for 3 days before cell inoculation and for 4 weeks thereafter, followed by $10 \mathrm{mg} / \mathrm{kg}$ per day for the last 4 weeks of the experiment [10]. CsA doses were adjusted weekly according to each animal's body weight.

During the 8-week followup, the animals were monitored daily for signs of CsA toxicity such as gingival hypertrophy, drooling, diarrhea, and weight loss.

2.2. Retinoblastoma Cell Line and Cell Culture. The human retinoblastoma WERI-Rb cells (ATCC HTB-169; American Type Culture Collection, Manassas, VA, USA) were cultured in RPMI 1640 medium with $2 \mathrm{mM}$ L-glutamine adjusted to contain $1.5 \mathrm{~g} / \mathrm{L}$ sodium bicarbonate, $4.5 \mathrm{~g} / \mathrm{L}$ glucose, $10 \mathrm{mM}$ HEPES, and $1.0 \mathrm{mM}$ sodium pyruvate, and $10 \%$ fetal bovine serum. The cells were grown in suspension at a concentration of $10^{5}-10^{6}$ cells $/ \mathrm{ml}$.

2.3. Cell Injection Procedure. At day 3, the animals received a $30 \mu \mathrm{l}$ subretinal injection of cultured WERI retinoblastoma cells $\left(1.5 \times 10^{6}\right.$ cells $)$. The procedure was performed under general anesthesia after intramuscular injection of Xylazine and Ketamine. The right eye (study eye) of each rabbit was dilated and anesthetized by application of Tropicamide $(0.1 \%)$ and Proparacaine $(0.5 \%)$, respectively. The surgery was performed with a surgical microscope (M691; Wild Heerbrugg, Heerbrugg, Switzerland) using a contact lens. This allowed for direct visualization of the fundus through the dilated pupil during injection of retinoblastoma cells. The eye was proptosed with a forceps and a sclerotomy was performed with a 25-gauge blade at the ora serrata at 2 o'clock position $2 \mathrm{~mm}$ from the limbus. A $50 \mu \mathrm{l}$ Hamilton syringe with a 30 -gauge blunt needle was inserted through the sclerotomy under microscopic direction until the retina was reached and subsequently perforated. A freshly prepared suspension $(30 \mu \mathrm{l})$ of cultured human WERI retinoblastoma cells $\left(1.5 \times 10^{6}\right.$ cells $)$ was injected into the subretinal space. The blunt needle was removed and the eye was examined for any signs of retinal detachment and possible intraretinal and/or intravitreal hemorrhage. A drop of $0.3 \%$ gentamicin eyedrop was applied to the right eye.
2.4. Ultrasound Examination. At week 4 after intraocular tumor inoculation, the rabbits were anesthetized with a mixture of Ketamine and Xylazine and ultrasound examination was performed on the right eye using 10-MHz B-scan (Compact Touch; Quantel Medical, Bozeman, MT).

2.5. Tissue Collection and Histopathologic Evaluation. Two rabbits were sacrificed each week until postoperatively 8 weeks with overdose of sodium pentobarbital $(65 \mathrm{mg} / \mathrm{kg})$. Digital fundus images were captured prior to euthanasia. After death, both eyes were enucleated and immediately fixed in $10 \%$ formalin. The eyes were serially sectioned and stained with hematoxylin-eosin. Light microscopic examination was performed on all histopathologic sections to evaluate the presence and extent of the tumor in the eye. The eyes were also evaluated for any evidence of extrascleral extension or optic nerve involvement of the tumor.

\section{Results}

The rabbits tolerated daily injection of CsA fairly well with occasional minor signs of CsA toxicity including gingival hypertrophy and drooling. One out of seventeen rabbits had to be sacrificed earlier than planned schedule at week 5 because of acute weight loss.

Subretinal injection of cultured retinoblastoma cells established a tumor in all the rabbits detectable with fundoscopy starting at postinjection week 1 (Figure 1(a)). The tumors became vascularized starting at week 5 (Figure 1(b)), and the tumor size continued to increase up to 8 weeks (Figures 1(c) and 1(d)). The B-scan ultrasound detected the presence of intraocular tumors in all the rabbits. The tumor was observed as a large mass in the posterior pole protruding into the vitreous cavity (Figure 2).

The histopathological examination showed that the tumors were present in all of the rabbits which received the subretinal injection. The rabbit model demonstrated similar fundus appearance and pathologic features to human retinoblastoma. The cells established a tumor in the subretinal space near the optic nerve and in the vitreous (Figure 3(a)). Occasional tumor seeds in the vitreous exhibited central necrosis (Figure 3(b)). Cuffs of viable tumor cells surrounded the blood vessels with regions of necrosis beginning 70-80 $\mu \mathrm{m}$ from central nutrient vessels (Figures $3(\mathrm{c})$ and 3(d)). Extrascleral extension of the tumor was not found in any of the animals.

\section{Discussion}

Although most eyes with International Classification Group A or B tumors are salvaged with chemoreduction and consolidation therapy, many eyes with Group C or D tumors are enucleated. Systemic chemotherapy for advanced retinoblastoma did not effectively treat the vitreous cavity [12]. A large number of treatment failures occur because of the progression of the tumor in the vitreous, where the concentration of the chemotherapeutic agents is low [13]. The salvage rate with chemotherapy and focal treatment for 


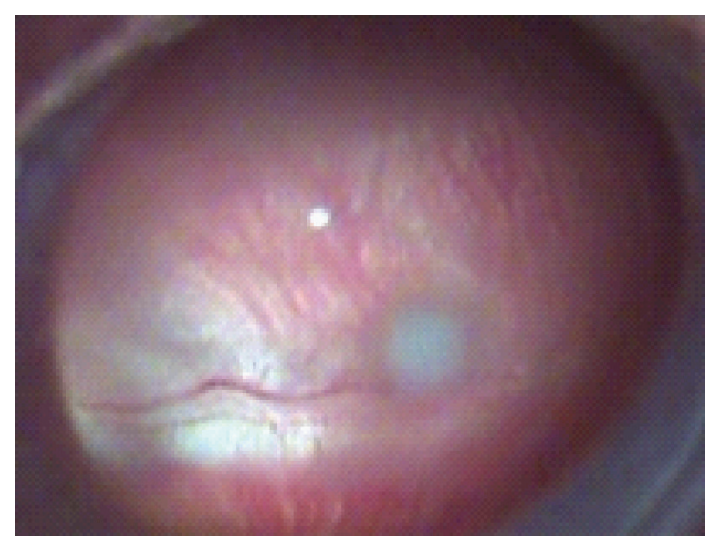

(a)

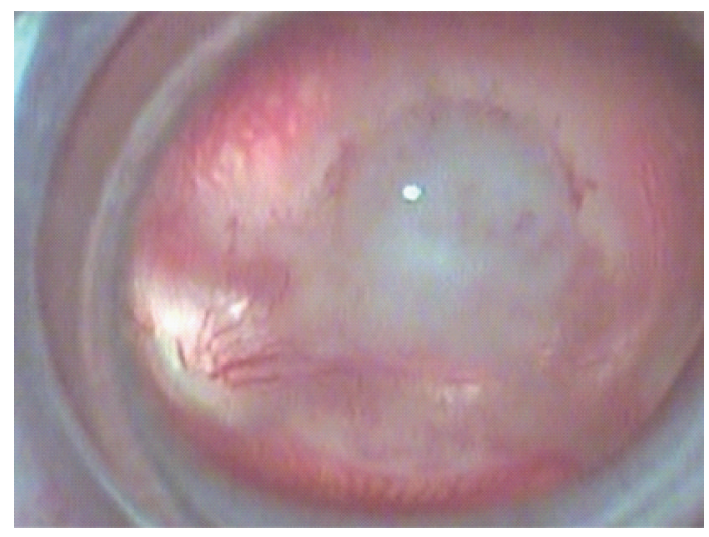

(c)

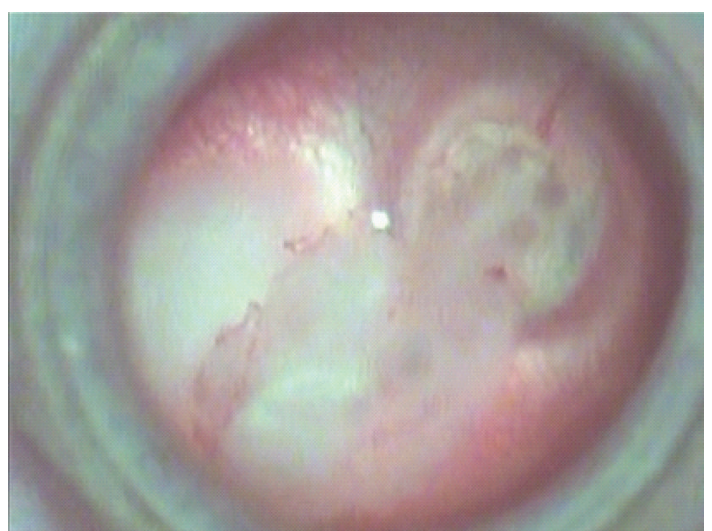

(b)

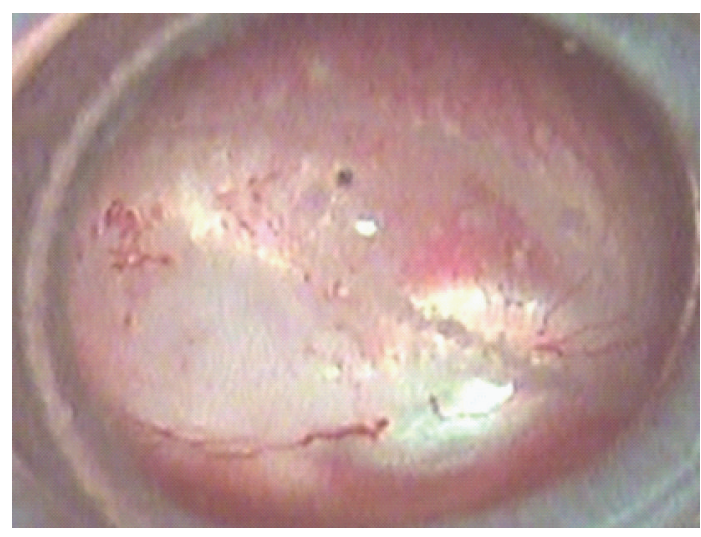

(d)

Figure 1: Fundus photos at postinjection 1 week (a), 6 weeks (b), 7 weeks (c), and 8 weeks (d). The retinoblastoma cells in the subretinal space established a tumor under the retina and in the vitreous. New vessel growth in the tumor was observed in vivo starting at postoperative week 5 .

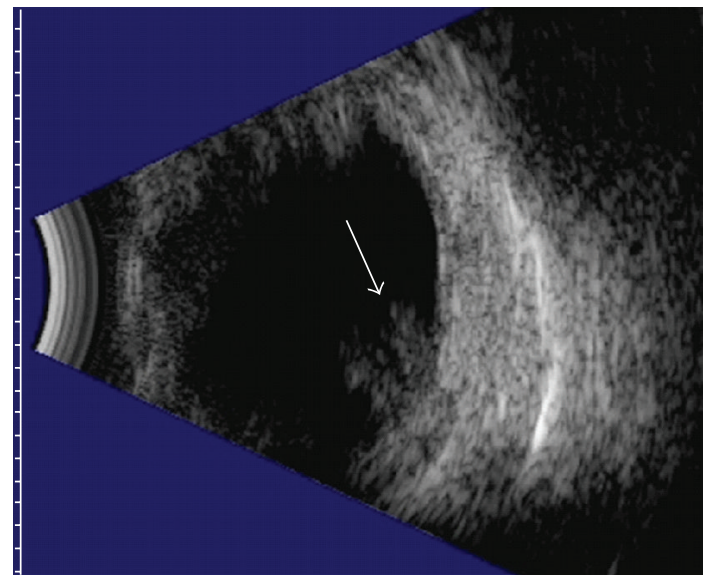

FIGURE 2: Ultrasound image at postinjection 6 weeks. The B scan image shows an intraocular tumor in the posterior pole in a rabbit eye (white arrow).

eyes with vitreous seeding was low, implicating the need for better treatment option for this group of patients [14]. Animal models of retinoblastoma are essential for identifying new therapies. The rabbit eye is similar in size to the human infant eye, and a rabbit retinoblastoma model is suitable for targeted drug delivery experiments.

Our rabbit model of retinoblastoma developed a tumor that closely resembles the human retinoblastoma clinically and histopathologically. The surgical procedure by experienced personnel caused minimal trauma to the retina, and there were no surgical complications observed. Minimal postoperative retinal bleeding was observed (1/17), which was resolved in a week with conservative management. No retinal detachments were observed.

Intraocular tumors developed in all of the rabbits, starting from week 1 . The tumor slowly grew under the retina and/or in the vitreous and continued to grow until the end of the study. The histopathological features resembled the findings in the human retinoblastoma. The tumor seeds in the vitreous space exhibited central necrosis, and there were cuffs of viable tumor cells surrounding the blood vessels. The subretinal tumor was confined to the retina posterior to the equator, and there was no evidence of invasion into the anterior compartment or outside of the sclera.

An animal model of retinoblastoma was first introduced by injecting human retinoblastoma cell into the immunocompromised mice. It was developed by transplanting Y79 


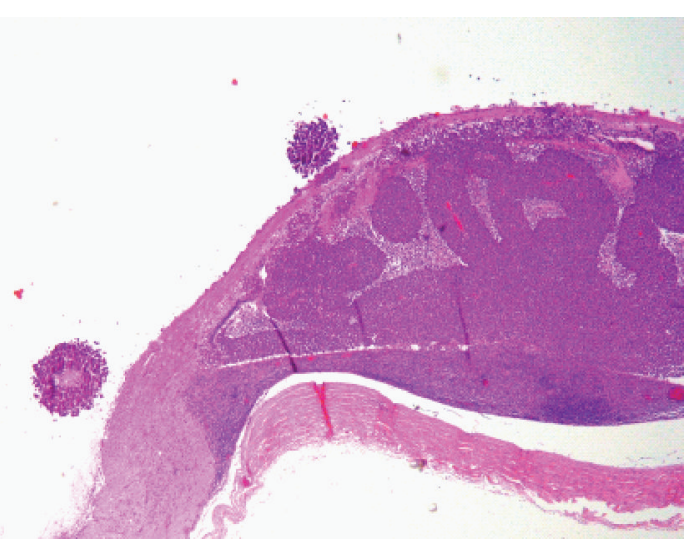

(a)

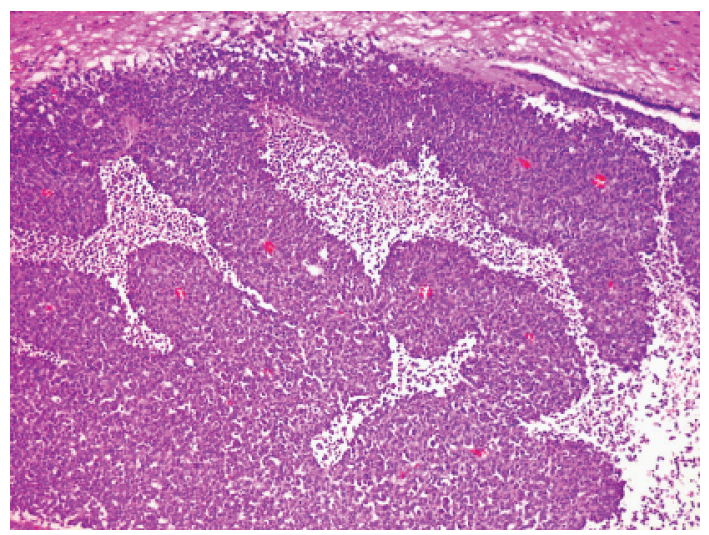

(c)

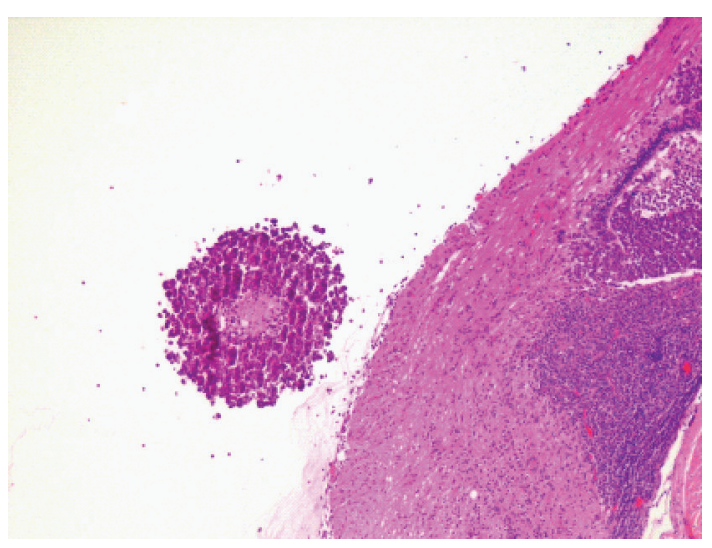

(b)

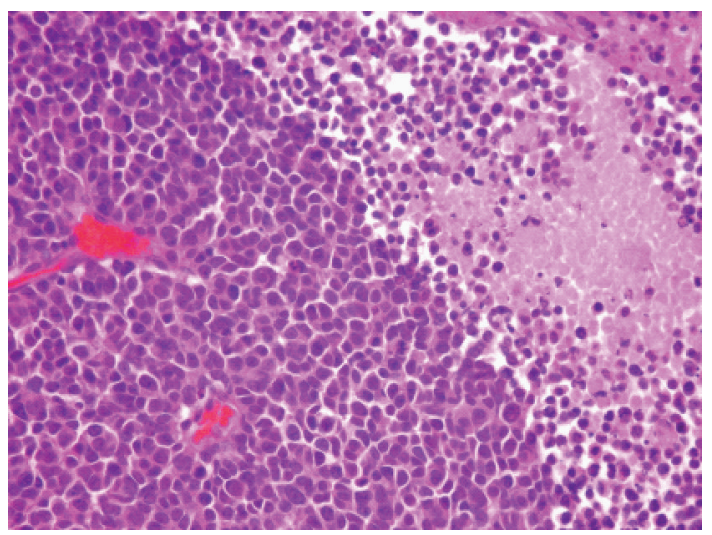

(d)

FIgURE 3: Histological findings at postinjection 7 weeks. Tumor was observed under the retina near optic nerve and in the vitreous (hematoxylin-eosin, $\times 40$, (a)). Occasional tumor seeds in the vitreous exhibited central necrosis $(\times 100$, (b)). Cuffs of viable tumor cells surrounded the blood vessels with regions of necrosis beginning $70-80 \mu \mathrm{m}$ from nutrient vessels $(\times 100,(\mathrm{c}) ; \times 400,(\mathrm{~d}))$.

human retinoblastoma cells into the flanks of immunocompromised mice, but it was not the ideal model because of obvious anatomic differences between the adult flank and the eye [15]. Another model was introduced by injecting human retinoblastoma cells (Y79 and WERI-Rb) into the vitreal cavities of immunodeficient mice [11]. Both cell lines developed an intraocular tumor in the immunodeficient mice, and WERI-Rb cells were predisposed to invade the anterior uveal tissues and lens. We did not find any evidence of invasion of the injected WERI-Rb cells into the anterior uvea and/or anterior chamber in our rabbit model.

Transgenic mice models are widely used as preclinical models to test new therapies for retinoblastoma. Human retinoblastoma cells show several genetic changes in addition to $\mathrm{Rb}$ inactivation [16], suggesting that $\mathrm{Rb}$ loss provides the capacity to proliferate and that another mutation is necessary for the dividing cells to be death resistant. From this observation, several knockout mouse models were introduced by deleting $\mathrm{Rb} 1$ gene and other proteins. Simian virus large $T$ antigen (Tag) inactivates both $R B$ and $p 53$, [17], and the LHbeta-Tag mice carry a transgene composed of the coding region of the SV 40 large $\mathrm{T}$ antigen driven by the promoter of the lutenizing hormone beta-subunit gene, developing multifocal, bilateral retinal tumors [9]. Other mouse knockout models were generated, involving mutation of $\mathrm{Rb}$ and p107, [18], Rb, p107 and p53 [19], and Rb and p130 [20]. However, our rabbit model has advantages over the mouse models. The main advantage for the use of rabbits is their larger eye size, which permits a more accurate injection of the drugs and evaluation of methods of targeted intraocular drug delivery. Another advantage is that our model includes vitreous seeds of viable tumor when the retinal tumor is mid-sized, which are usually found in the late stage in mouse models $[18,20]$. The lack of ability to eliminate vitreous seeds is a major reason of current treatment failures in Group C and D tumors [12-14]. The major limitations of our model are that we used commercially available retinoblastoma cell lines, which may have a different drug sensitivity pattern than wild-type cells. Also, the implanted cells grow from the subretinal space, not from the retina itself as it would happen in humans. Therefore, we believe our rabbit model will serve as a model to test the efficacy of new chemotherapeutic agents. 


\section{Conclusions}

Subretinal injection of cultured retinoblastoma cells established a tumor in all rabbits in our study. Tumor size continued to increase up to 8 weeks, and the tumors became vascularized starting at week 5 . The rabbit model demonstrated similar fundus appearance and pathologic features to human retinoblastoma, including vitreous seeds of viable tumor. This rabbit model of retinoblastoma may be used as a model to evaluate the effectiveness of various routes of drug delivery.

\section{Acknowledgments}

This work has been presented in part at the annual meeting for Association for Research in Vision and Ophthalmology, May 4, 2009, Fort Lauderdale, FL, supported in part by NIH NEI R24 EY017045, P30 EY06360, and an unrestricted departmental grant from Research to Prevent Blindness, Inc. The authors have no proprietary interests in the materials present in the manuscript.

\section{References}

[1] F. L. Wong, J. D. Boice Jr., D. H. Abramson et al., "Cancer incidence after retinoblastoma: radiation dose and sarcoma risk," Journal of the American Medical Association, vol. 278, no. 15, pp. 1262-1267, 1997.

[2] D. H. Abramson and C. M. Frank, "Second nonocular tumors in survivors of bilateral retinoblastoma: a possible age effect on radiation-related risk," Ophthalmology, vol. 105, no. 4, pp. 573-580, 1998.

[3] G. J. Draper, B. M. Sander, and J. E. Kingston, "Second primary neoplasms in patients with retinoblastoma," British Journal of Cancer, vol. 53, no. 5, pp. 661-671, 1986.

[4] L. B. Travis, E. J. Holowaty, K. Bergfeldt et al., "Risk of leukemia after platinum-based chemotherapy for ovarian cancer," The New England Journal of Medicine, vol. 340, no. 5, pp. 351-357, 1999.

[5] M. A. Smith, L. Rubinstein, J. R. Anderson et al., "Secondary leukemia or myelodysplastic syndrome after treatment with epipodophyllotoxins," Journal of Clinical Oncology, vol. 17, no. 2, pp. 569-577, 1999.

[6] J. H. Gerlach, N. Kartner, D. R. Bell, and V. Ling, "Multidrug resistance," Cancer Surveys, vol. 5, no. 1, pp. 25-46, 1986.

[7] D. H. Abramson, C. M. Frank, and I. J. Dunkel, "A phase I/II study of subconjunctival carboplatin for intraocular retinoblastoma," Ophthalmology, vol. 106, no. 10, pp. 19471950, 1999.

[8] I. Schmack, G. B. Hubbard, S. J. Kang, T. M. Aaberg, and H. E. Grossniklaus, "Ischemic necrosis and atrophy of the optic nerve after periocular carboplatin injection for intraocular retinoblastoma," American Journal of Ophthalmology, vol. 142, no. 2, pp. 310-e2, 2006.

[9] J. J. Windle, D. M. Albert, J. M. O’Brien et al., "Retinoblastoma in transgenic mice," Nature, vol. 343, no. 6259, pp. 665-669, 1990.

[10] P. L. Blanco, J. C. A. Marshall, E. Antecka et al., "Characterization of ocular and metastatic uveal melanoma in an animal model," Investigative Ophthalmology and Visual Science, vol. 46, no. 12, pp. 4376-4382, 2005.
[11] P. Chevez-Barrios, M. Y. Hurwitz, K. Louie et al., "Metastatic and nonmetastatic models of retinoblastoma," American Journal of Pathology, vol. 157, no. 4, pp. 1405-1412, 2000.

[12] M. W. Wilson, C. Rodriguez-Galindo, B. G. Haik, D. M. Moshfeghi, T. E. Merchant, and C. B. Pratt, "Multiagent chemotherapy as neoadjuvant treatment for multifocal intraocular retinoblastoma," Ophthalmology, vol. 108, no. 11, pp. 21062114, 2001.

[13] D. L. Friedman, B. Himelstein, C. L. Shields et al., "Chemoreduction and local ophthalmic therapy for intraocular retinoblastoma," Journal of Clinical Oncology, vol. 18, no. 1, pp. 12-17, 2000.

[14] C. Rodriguez-Galindo, M. W. Wilson, B. G. Haik et al., "Treatment of intraocular retinoblastoma with vincristine and carboplatin," Journal of Clinical Oncology, vol. 21, no. 10, pp. 2019-2025, 2003.

[15] L. White, C. Reed, and V. Tobias, "Comparison of cyclophosphamide and diaziquone in a retinoblastoma xenograft model," Ophthalmic Paediatrics and Genetics, vol. 10, no. 2, pp. 99-105, 1989.

[16] D. Chen, S. Pajovic, A. Duckett, V. D. Brown, J. A. Squire, and B. L. Gallie, "Genomic amplification in retinoblastoma narrowed to 0.6 megabase on chromosome $6 \mathrm{p}$ containing a kinesin-like gene, RBKIN," Cancer Research, vol. 62, no. 4, pp. 967-971, 2002.

[17] J. A. Mietz, T. Unger, J. M. Huibregtse, and P. M. Howley, "The transcriptional transactivation function of wild-type p53 is inhibited by SV40 large T-antigen and by HPV-16 E6 oncoprotein," The EMBO Journal, vol. 11, no. 13, pp. 50135020, 1992.

[18] D. Chen, I. Livne-bar, J. L. Vanderluit, R. S. Slack, M. Agochiya, and R. Bremner, "Cell-specific effects of RB or RB/p107 loss on retinal development implicate an intrinsically death-resistant cell-of-origin in retinoblastoma," Cancer Cell, vol. 5, no. 6, pp. 539-551, 2004.

[19] J. Zhang, B. Schweers, and M. A. Dyer, "The first knockout mouse model of retinoblastoma," Cell Cycle, vol. 3, no. 7, pp. 952-959, 2004.

[20] D. MacPherson, J. Sage, T. Kim, D. Ho, M. E. McLaughlin, and T. Jacks, "Cell type-specific effects of Rb deletion in the murine retina," Genes and Development, vol. 18, no. 14, pp. 1681-1694, 2004. 


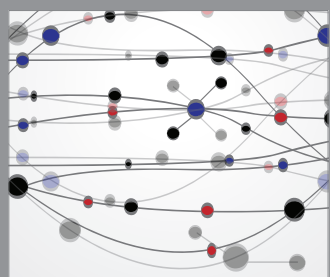

The Scientific World Journal
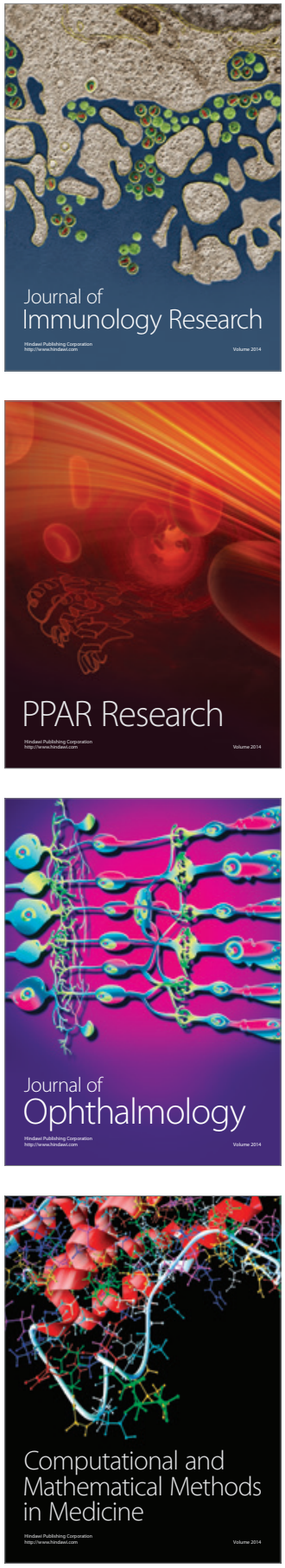

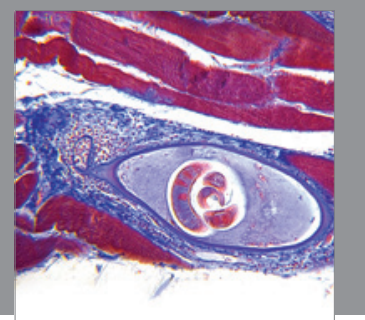

Gastroenterology

Research and Practice
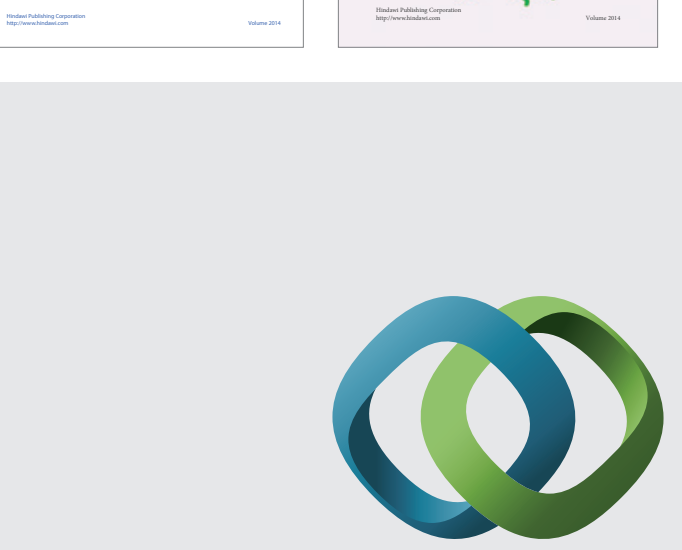

\section{Hindawi}

Submit your manuscripts at

http://www.hindawi.com
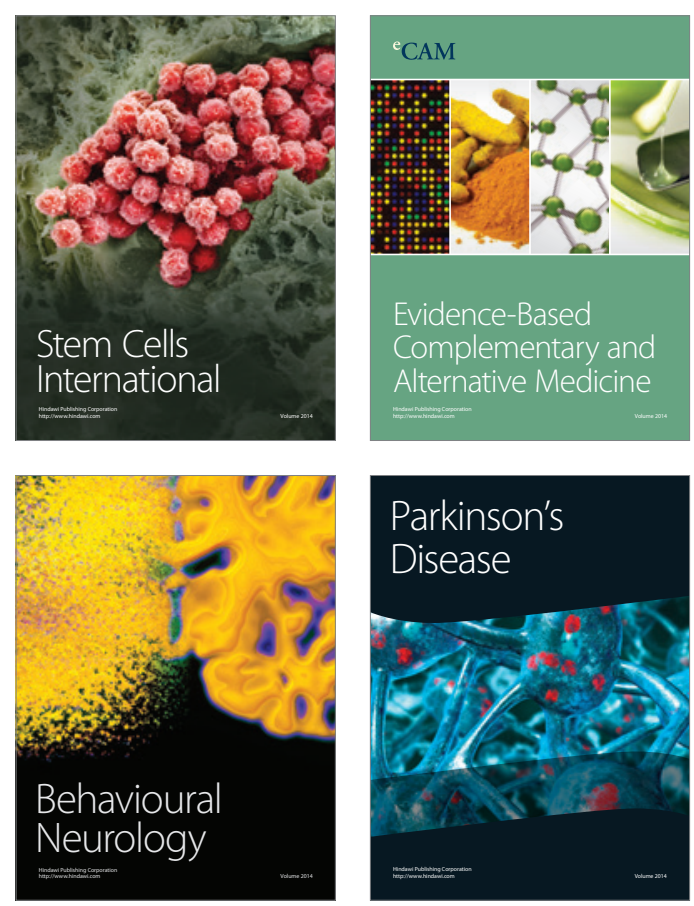

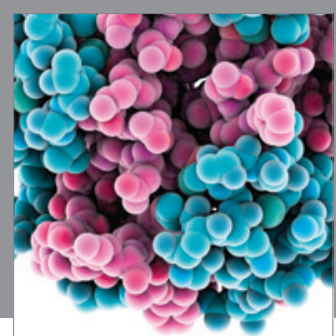

Journal of
Diabetes Research

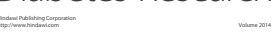

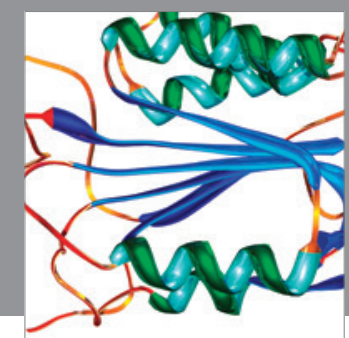

Disease Markers
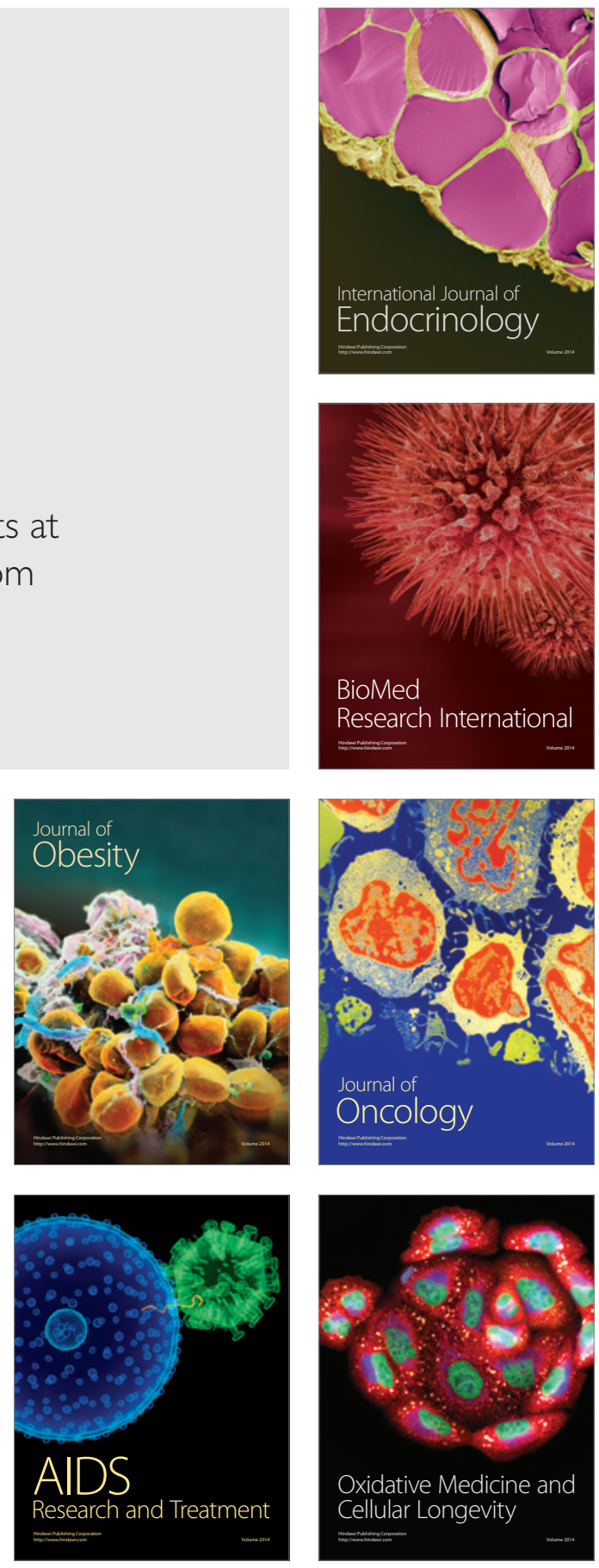